\title{
СОСТОЯНИЕ СЕРДЕЧНОСОСУДИСТОЙ СИСТЕМЫ СТУДЕНТОВ ПРИ ВОЗДЕЙСТВИИ ГОРНОЙ ГИПОКСИИ
}

\section{STATE OF THE CARDIOVASCULAR SYSTEM OF STUDENTS UNDER EXPOSURE TO MOUNTAIN HYPOXIA}

\author{
V. Anzorov \\ S. Moryakina
}

Summary: The article describes the state of the cardiovascular system of students living in a mountainous area. From the above data, we can conclude that hypoxia does not lead to significant changes in the indicators of the cardiovascular system of young people. The heart rate, systolic, diastolic pressure of female students and their peers, gradually decreasing, reach the minimum values in the midlands -74.2 beats per minute, $113.2 ; 75.0 \mathrm{mmHg}$ st and $70.4 ; 114.6 ; 73.0$, and at an altitude of $170 \mathrm{~m}-77.4 ; 116.4 ; 78.2 \& 73.6 ; 118.8 ; 76.4$ respectively. The fluctuation range of the average $E C G$ values is not significant.

Keywords: student, mountains, hypoxia, heart, electrocardiogram.
Анзоров Ваха Асхадович

Д.б.н., профессор, Чеченский государственный университет vaha-anzorov@mail.ru

Морякина Светлана Васильевна К.б.н., дочент, Чеченский государственный университеm s.moriakina@yandex.ru

Аннотация: В статье приведено состояние сердечнососудистой системы студентов, проживающих в горной местности. Из приведенных данных можно заключить, что гипоксия не приводит к значительным изменениям показателей сердечнососудистой системы молодежи. Сердечный ритм, систолическое, диастолическое давление студенток и их сверстников постепенно снижаясь, достигают минимальных значений в среднегорье - 74,2 ударов в минуту, 113,2; 75,0 мм рт. ст. и 70,4; 114,6; 73,0, а на высоте 170 м - 77,4; 116,$4 ; 78,2$ и 73,6; 118,8; 76,4 соответственно. Диапазон колебания средних величин ЭКГ не существенен.

Ключевые слова: студент, горы, гипоксия, сердце, электрокардиограмма.

\section{Введение}

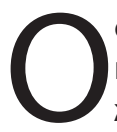
собенность жизни человека в современном обществе состоит в постоянном увеличении напряжения систем организма из-за воздействия различных климатических, информационных, социальных и других важных факторов внешней среды. Это в свою очередь вызывает необходимость в увеличении адаптивных возможностей организма. Поэтому проблема приспособления к гипоксии является одной из важных в физиологии. Горами считаются земли, находящие на высоте не менее 500 м над уровнем моря. Средней высотой расположения земной суши является 875 метров.

На долю горных массивов в земной суше приходится 40\% и проживает здесь 600 млн. человек. Заселенным является и высокогорье, охватывающее до 4500 метров высоты. В советское время доля населения горных районов составляло не менее $20 \%$. Основными причинами, заставившими человека заселить горную местность Земли, являются: поиск новых источников энергии и полезных ископаемых; строительство спортивных и оздоровительных сооружений. Особенностью горных районов является их богатство различными ресурсами: водными; земельными; лесными; пастбищными и другими.

Горные районы в отличие от других природных зон обладают большим разнообразием природно-климатических условий. Снижение уровня кислорода в атмос- ферном воздухе является наиболее значимым из факторов, влияющих на человека в горах.

Джон Банкрофт писал, что из веществ необходимых для жизнедеятельности организма наиболее важным является кислород. Исследования по изучению высотной гипоксии начатые Х. Соссюром, П. Бэром, И.М. Сеченовым, А. Моссо, Н. Цунтци, Дж. Холдейном, Дж. Баркрофтом и Н.Н. Сиротининым способствовали становлению и развитию горной физиологии и медицины.

Особенность горного воздуха, на которую необходимо обратить особое внимание состоит в том, что он беден микрофлорой. Благодаря чему жители горных районов обладают хорошим здоровьем и высокой работоспособностью, которые сохраняются до старости [2].

Человек впервые сталкиваясь с гипоксией еще в организме матери сохраняет эту связь до конца своей жизни. Установлено, что организмы в 1,5-2,0 раза дольше живут в условиях гор, чем на равнине. Также длительность жизни людей на высоте 2500 метров на 15-20 лет выше, чем в обычных условиях. Отрадно то, что все рекорды по продолжительности жизни были установлены в горной местности. Так М. Эйвазов, житель горного села Азербайджана прожил 152 года. Процесс адаптации человека к условиям гор имеет индивидуальные особенности, наиболее важными из которых являются следующие: состояние его здоровья; переносимость дефицита кисло- 
рода; степень и время воздействия нехватки кислорода. Приспособление к климату гор, является эффективным методом увеличения продолжительности жизни, писали Н. Агаджанян и А. Катков в книге «Резервы нашего организма». Изучением горной гипоксии занялись значительно раньше, чем других видов. Обусловлено это тем, что горы всегда привлекали людей как неизведанностью, привлекательностью, не покорностью вершин, так, и развитием горных видов спорта, воздухоплавания, авиации и космонавтики, считает В.А. Березовский [4]. Наши предки использовали высотную гипоксию для повышения работоспособности [3]. Отсутствие эффективных методов лечения многих заболеваний привело к тому, что еще в конце 19-го и в начале 20-го столетия лечение горным воздухом получило широкое распространение. Использование горного климата для лечения различных болезней впервые было предложено нашим ученым Н.Н. Сиротининым. Воздух гор оказывает благоприятное воздействие, как на воспалительные заболевания, так, и на остаточные воспалительные явления.

Воздействие гипоксии и сегодня используется для повышения сопротивляемости организма спортсменов [13; 14]. По результатам исследований, проведенных в настоящее время, установлено, что терапия гипоксией успешно используется для улучшения физического, умственного и психического состояния организма, повышения иммунитета, нормализации всех видов обмена веществ, стимуляции кровообращения и обмена энергии [7; 6]. По данным Н.И. Лосева [7] и А.3. Колчинской [6] широко используют различные лечащие механизмы терапии гипоксией для повышения общей работоспособности и переносимости различных воздействий.

Высокий интерес со стороны физиологов и медиков к вопросам связанным с адаптацией к различным типам гипоксии обусловлен тем, что при этом происходит повышение функциональной деятельности как обеспечивающих, так, и транспортирующих и утилизирующих кислород систем организма и эта особенность используется при подготовке спортсменов [5, 9]. Для мобилизации систем организма в большом спорте широко используются различные методы воздействия гипоксией.

Повышение эффективности функционирования систем организма является одной из важных проблем современности, так, как направлено на укрепление и сохранение его здоровья, повышение работоспособности и продление жизни. Превосходство немедикаментозных средств оптимизации систем организма состоит в их отсутствии побочного влияния на организм. Один из таких способов использование гипоксической гипоксии для повышения функционального состояния систем организма получил широкое использование в авиационной, космической и морской медицине еще с середины 20-го столетия. Воздействие горным климатом, а также трени- ровки в барокамерах являются широко используемыми методами гипоксической гипоксии. Важность изучения вопросов связанных с адаптацией человека к условиям высотной гипоксии связано с увеличением миграции населения в горные районы [10]. В проблеме гипоксии все еще остаются нерешенные вопросы. Одним из таких является вопрос об изменениях, происходящих со стороны жизненно важных систем организма в условиях гипоксии.

Таковыми являются системы крови, дыхания и кровообращения, которые относятся к газотранспортной системе организма. Учитывая, что проблема гипоксии является многоплановой, характер изменений вызываемых ею по улучшению функциональной деятельности систем организма, может быть успешно использована при адаптации молодежи к учебной деятельности, так как она требует мобилизации всех функциональных резервов. Особенности механизмом адаптации человека к дефициту кислорода в горном воздухе и наступающие при этом негативные последствия, все еще остаются недостаточно изученными [8].

Учитывая, что сердечнососудистая система обеспечивает клетки, ткани и органы организма питательными веществами и кислородом изучение состояния этой системы у студентов в условиях гипоксии является важным.

\section{Материалы и методика исследований}

Работа выполнена в лаборатории физиологии на 30 студентах, 15 из них девушки. Обучающиеся находились в возрасте 19-21 лет. При делении их на три группы учитывали пол и высоту проживания над уровнем моря. Группа состояла их пяти студенток и 5 их сверстников.

Для сбора экспериментального материала использовали электрокардиограф Альтон-03 и тонометр OMRON M3 Expert.

Компьютерная программа «Биостатистика» была использована для статистической обработки полученных данных.

\section{Результаты исследований и их обсуљкение}

Изменения показателей сердечнососудистой системы молодежи в условиях высотной гипоксии приведены в таблице 1 и на рисунке 1.

Результаты проведенных исследований показывают, что недостаточный уровень кислорода в атмосферном воздухе не вызывает существенных сдвигов в показателях сердечнососудистой системы студентов. Ритм сокращения сердца ниже у девушек и юношей в условиях низ- 
Таблица 1.

Динамика показателей сердечно-сосудистой системы студентов в условиях горной гипоксии

\begin{tabular}{|c|c|c|c|c|c|c|}
\hline \multirow[t]{3}{*}{ Показатели } & \multicolumn{6}{|c|}{ Место проживания } \\
\hline & \multicolumn{2}{|c|}{ г. Грозный } & \multicolumn{2}{|c|}{ Шатой } & \multicolumn{2}{|c|}{ Шарой } \\
\hline & Юноши & Девушки & Юноши & Девушки & Юноши & Девушки \\
\hline ЧСС, ударов в минуту & $73,6 \pm 2,38$ & $77,4 \pm 2,98$ & $72,0 \pm 2,21$ & $76,2 \pm 2,63$ & $70,4 \pm 2,38$ & $74,2 \pm 2,65$ \\
\hline Систолическое давление, мм рт. ст. & $118,8 \pm 4,33$ & $116,4 \pm 4,55$ & $118,0 \pm 4,21$ & $115,8 \pm 4,45$ & $114,6 \pm 4,16$ & $113,2 \pm 4,59$ \\
\hline Диастолическое давление, мм рт. ст. & $76,4 \pm 3,56$ & $78,2 \pm 4,16$ & $75,8 \pm 3,89$ & $77,4 \pm 4,19$ & $73,0 \pm 3,46$ & $75,0 \pm 4,27$ \\
\hline $\mathrm{P}, \mathrm{C}$ & $0,090 \pm 0,0033$ & $0,088 \pm 0,0056$ & $0,090 \pm 0,0027$ & $0,087 \pm 0,0041$ & $0,089 \pm 0,0043$ & $0,089 \pm 0,0063$ \\
\hline$P Q, c$ & $0,144 \pm 0,0072$ & $0,142 \pm 0,0051$ & $0,146 \pm 0,0046$ & $0,143 \pm 0,0051$ & $0,147 \pm 0,0049$ & $0,145 \pm 0,0034$ \\
\hline QRS, C & $0,068 \pm 0,0014$ & $0,069 \pm 0,0034$ & $0,070 \pm 0,0023$ & $0,070 \pm 0,0036$ & $0,069 \pm 0,0026$ & $0,068 \pm 0,0031$ \\
\hline QT, C & $0,339 \pm 0,0078$ & $0,342 \pm 0,0090$ & $0,344 \pm 0,0069$ & $0,347 \pm 0,0086$ & $0,348 \pm 0,0069$ & $0,355 \pm 0,0081$ \\
\hline
\end{tabular}

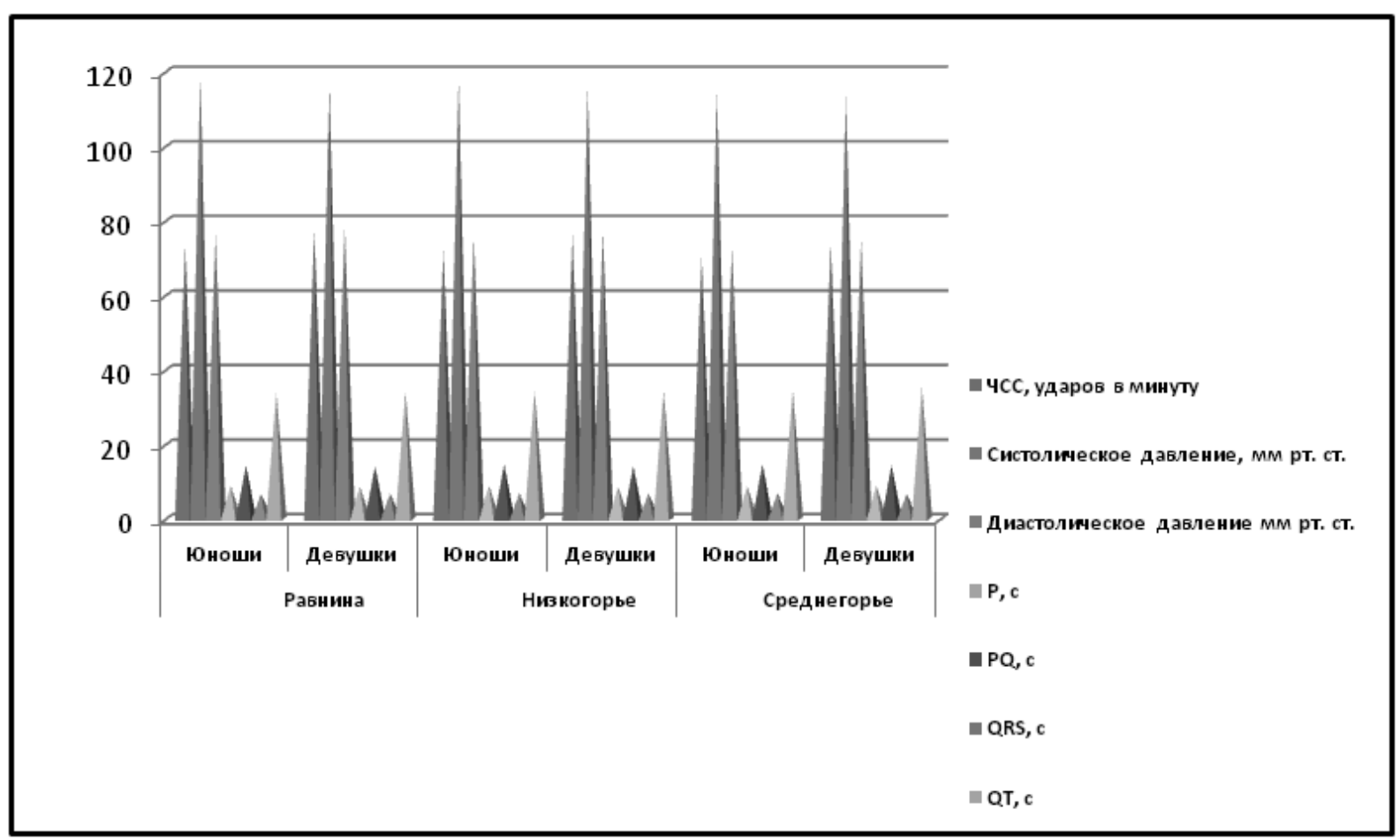

Рис. 1. Состояние сердечнососудистой системы студентов в условиях горной гипоксии

когорья на 1,2 и 1,6 ударов в минуту, среднегорья - 3,2 и 3,2, чем на равнине - 77,4 и 73,6.

Средний уровень высокого давления крови ниже на 3,2 мм рт. ст. у жительниц среднегорья, а у их сверстников на 4,2, чем равнины.

Низкое артериальное давление у студенток и юношей снижается до минимальной величины - 75,0 и 73,0 мм рт. ст. в условиях среднегорья, а на равнине составляет 78,2 и 76,4.

Наши данные подтверждаются результатами исследований других авторов.
Начало приспособления к гипоксии сопровождается увеличением частоты сердечных сокращений и минутного объема кровообращения [15].

Минутный объем крови растет из-за учащения сокращений сердца и увеличения систолического выброса крови.

В дальнейшем значения этих показателей снижается ниже исходных, утверждает В.А. Березовский [4].

Вероятно, снижение частоты сердечных сокращений обусловлено усилением возбудимости парасимпатической нервной системы. 
К аналогичным выводам в своих исследованиях пришли и другие исследователи. При воздействии гипоксии активность центральной нервной системы меняется. В начальный период воздействия гипоксии обладает высокой активностью симпатическая нервная система, а по мере углубления гипоксии преобладает парасимпатическая, считают Н.А. Агаджанян и М.М. Миррахимов [1].

К таким же выводам в своих исследованиях пришел [10]. Размах между максимальными и минимальными значениями времени охвата возбуждением предсердий и желудочков, как у юношей, так и их сверстниц составляет лишь 0,002 с. Возбуждение от предсердий к желудочкам проводится у девушек и юношей в низкогорье на 0,001 и 0,002 с, а среднегорье - 0,003 и 0,003 с медленнее, чем на равнине.

Удлинение времени систолы желудочков на высоте 600 и 1600 метров у юношей составляет 0,005 и 0,009 с, у девушек - 0,005 и 0,013 с, чем на высоте 170 метров.

Мы не нашли литературных источников о последствиях воздействии горного воздуха на продолжительность зубцов и интервалов ЭКГ подростков.

Однако очевидно, что эти изменения связаны со снижением выработки адреналина. При дефиците кисло- рода выработка гормонов надпочечниками падает [12]. Westendorp R.G.J. [et al.] [12] сообщает, что в условиях нехватки кислорода вес и размеры надпочечников возрастают, при углублении гипоксии функция их снижается.

Из результатов проведенных нами исследований можно заключить, что горная гипоксия не вызывает значительных изменений показателей сердечнососудистой системы студентов. Так ритм сокращения сердца и артериальное давление крови снижаются, продолжительность зубцов и интервалов увеличивается.

\section{Выводы}

1. Проживание в условиях горной гипоксии не приводит к значительным изменениям показателей сердечнососудистой системы студентов.

2. Частота сердечных сокращений на высоте 1600 м падает у юношей до 70,4 ударов в минуту, а у сверстниц до 74,2, а на равнине составляет 73,6 и 77,4 соответственно.

3. Величина систолического и диастолического давления крови студенток ниже на высоте 1600 метров на 3,2 и 3,2 мм рт. ст., а юношей на 4,2 и 3,4, чем 170.

4. Показатели ЭКГ студентов с увеличением высоты проживания подвергаются к колебаниям в обе стороны.

\section{ЛИТЕРАТУРА}

1. Агаджанян Н.А., Миррахимов М.М. Горы и резистентность организма. М.: Наука, 1970. 184 с.

2. Агаджанян Н.А., Елфимов А.И. Функции организма в условиях гипоксии и гиперкапнии. М., 1986. С. 45-67.

3. Агаджанян Н.А., Баевский Р.М., Берсенева А.П. Проблемы адаптации и учение о здоровье. М.: РУДН, 2006. С. 284.

4. Гипоксия и индивидуальные особенности реактивности / под ред. В.А. Березовского. Киев, 1978. С. 76-91.

5. Иорданская Ф.А. Гипоксия в тренировке спортсменов и факторы,повышающие ее эффективность // Советский спорт. М., 2015. С. 160.

6. Колчинская А.З. Кислород. Физическое состояние. Работоспособность. Киев: Наукова думка, 1991. 206 с.

7. Лосев Н.И., Хитров Н.К., Грачев С.В. Патофизиология гипоксических состояний и адаптации организма к гипоксии. М., 1982. С. 25-47.

8. Новиков В.С. Гипоксия // Горная гипоксия. СПб., 2000. С. 24-58.

9. Платонов В.Н. Система подготовки спортсменов в олимпийском спорте // 2015, Кн. 2. С. 752.

10. Хадарцев А.А. Неспецифические (синтаксические и кататоксические) механизмы адаптации к длительному воздействию холодового раздражителя // Вестник новых медицинских технологий. 2000. Т. 7. № 3-4. С. 100-105.

11. Westendorp R.G.J. et al. Effects of hypoxia and atrial natriuretic peptide on aldosterone secretion in healthy subjects // Journal of Applied Physiology. 1993 . № 75. Pp. 534-539.

12. Weil J.V. et al. Hypoxic ventilatory drive in normal man. Journal of Clinical Investigation. 1970. № 49. Pp. 1061-1072.

13. Ponsot E. Exercise training in normobaric hypoxia in endurance runners. I. Improvement in aerobic performance capacity // J. Appl. Physiol. 2007. № 103 (2). P. 730.

14. Richalet J.P., Gore C.J. Live and/or sleep high: train low, using normobaric hypoxia // J. Med. Sci. Sports. 2008. Vol. 18. № 1. P. $29-37$.

15. Boussuges A. et al. Operation Everest III: Modifications of cardiac function secondary to altitude-induced hypoxia. An echocardiographic and doppler study // American Journal of Respiratory and Critical Care Medicine. 2000. № 161. P. 264-270. 